http://jmscr.igmpublication.org/home/ ISSN (e)-2347-176x ISSN (p) 2455-0450

crossref DOI: https://dx.doi.org/10.18535/jmscr/v9i2.29

\author{
Journal Of Medical Science And Clinical Research \\ IGM Publication \\ An official Publication of IGM Publication
}

\title{
The effect of endocrine disruptors on endometrial cells: A Systematic Review
}

\author{
Authors \\ Muna Omer Alamoudi, Nada Ibrahim Alaqah, Ebtisam Ahmad Alrshedy, \\ Latifa Ghazi Alshaya
}

Biology Department, Faculty of Science, University of Hail PO Box 2240, Hai'l 81451, Saudi Arabia

\begin{abstract}
Endocrine disruptor plays a role as natural hormones in the body like estrogens or androgens, or thyroid hormones. It may act as the interaction of natural hormones with their receptor, or bind to a receptor and prevent the endogenous hormone from binding with their receptors. Endometrial tissue finds in uterus has gland, cells, and connective tissue. This tissue prepares the uterus for ovulation. The objectives of this review were to identify the effect of endocrine disruptors on endometrial cells. Electronic searches of literature were performed. From 38 titles, Full-text versions of the 15 identified titles were obtained and evaluated independently by two reviewers 8 of the full-text articles were excluded based on the established criteria. This process identified 7 articles for inclusion and data extraction. According the existing literatures, this study concluded that endocrine disruptors can affect on endometrial cells by regulate the expression of decidualization genes. But it can also cause endometrial dysfunction, disrupt vascular development and play important roles in tumorigenesis. The existing literatures reporting on this are small in volume and can be considered of generally low quality.

Keyword: Endocrine, Disruptors, Endometrial Cells, Endometrial Decidualization, Bisphenol A.
\end{abstract}

\section{Introduction and Literature Review}

\subsection{Endocrine System and Hormone.}

The body function controlled by communication between various parts and organs, this communication maintains by two system: the nervous system, and the hormonal system. Also, the endocrine system has a continuous reaction with other main communication systems of body, the nervous system, and the immune system, so any error of the endocrine system may impact these other systems (Demeneix et al., 2019). Hormones are molecules produced by endocrine glands, the interaction between the hormones and its receptor produce a cascade of biochemical reactions in the target cell that produce modification on the cell's function or activity (Hiller-Sturmhöfel \& Bartke, 1998). The endocrine system regulates physiological systems: growth of the skeleton and muscles, reproduction, control of body temperature, brain development, and brain activity (Demeneix et al., 2019). The concept of endocrine function was expanded to paracrine, autocrine, juxtacrine, and intracrine functions, instead of the classic endocrine system, which has the traditional endocrine axes (Chrousos, 2007). 


\subsection{Endocrine Distruption.}

Large numbers and large quantities of man-made chemicals present in the environment since World War II that are potentially capable of modulating and/or disrupting the endocrine system, this chemical called endocrine disruptors (Colborn et al., 1994) .Endocrine disrupter is asubstance or mixture that distrupt function of the endocrine system and causes defect on health in an intact organism, or populations." (WHO | World Health Organization, 2002). Another definition is exogenous agents that interfere with the synthesis and actionof endocrine hormones that are affect on the maintenance of development of human body (Markey et al., 2002)

There is many Man-made chemicals have been reported to act as hormone mimics include: organochlorine pesticides (DDT and its metabolites, endosulfan, toxaphene, $\beta-\mathrm{HCH}$, and dieldrin), polychlorinated biphenyls (PCBs; both mixtures and individual congeners) and their hydroxylated metabolites, dioxin-like chemicals (PCDDs and PCDFs), bisphenol-A (a chemical used in the manufacture of polycarbonate-derived products and epoxy resins), alkylphenolic chemicals (products of the degradation of industrial surfactants and antioxidants), vinclozolin (a fungicide), tributyl tin (TBT; an anti-fouling compound) and a few phthalates (widely used as plasticizers) (Tyler et al., 1998).

Endocrine disruptor plays a role as natural hormones in the body like estrogens or androgens, or thyroid hormones. It may act as the interaction of natural hormones with their receptor, or bind to a receptor and prevent the endogenous hormone from binding. Such as chemicals that prevent hormones are anti-estrogens and anti-androgens. This interference produces adverse developmental, reproductive, neurological, and immune effects in both humans and wildlife (Monneret, 2017).

\subsection{Endometrial Cells.}

Endometrial tissue finds in uterus has gland, cells, and connective tissue. This tissue prepares the uterus for ovulation. Normal endometrial cells mustn't find after menopause, when these endometrial cells grow abnormally or spread to other organs of the body so, it become tumors. This can detect by endometrial biopsy. This cancer that starts in the inner layer of uterus called endometrial cancer. In this study report that the shedding of normal endometrial cells by women who are postmenopausal indication for abnormal finding that may be because of presence of endometrial carcinoma(Gomez-Fernandez et al., 2000). In other study reported about accuracy of endometrial biopsy in diagnosis of endometrial cancers, that concluded this type of biopsy has high accuracy in diagnosis of endometrial cancer (Clark et al., 2002).

\subsection{Effect of endocrine disruptors on endometrial Cells.}

All organs of body that controlled by hormones can affected by endocrine disruptors. So, the endocrine disruptors can be associated with disability, deformity, sexual development and brain problems. The living environment determines the number of endocrine disruptors. And these EDs contribute as important factor for woman organ disorders (la Rocca et al., 2015). The carcinogenic effects of endocrine disruptors are reasonable, but their mechanisms unclear (Mallozzi et al., 2017).

\subsection{Endometrial Decidualization and Bisphenol} A.

Bisphenol A (BPA) is a common endocrine disruptor exposed human life, from prenatal to adult age. Endometrial decidualization is aprocess of pregnancy, with which the uterus prepares for embryo implantation. Decidualization of endometrial stromal cells is important for successful pregnancy and outcomes (Gellersen \& Brosens, 2014). 


\section{Materials and Methods \\ Search Strategy}

This systematic review was intended to identify the effect of endocrine disruption on endometrial cells. Key words were chosen to include endocrine, disruptors, and endometrial cells.

A Medline (PubMed) search was undertaken to identify randomized controlled trials, systematic review, cohort studies and case series.

\section{Selection of Studies}

Two of the authors independently screened the titles and abstracts obtained from the electronic search for inclusion or exclusion. Disagreements were resolved via direct discussion. Full-text versions of articles were obtained when compliance with the criteria required for the review was positive or when exclusion could not be confirmed.

Five reviewers independently per formed a review of the full-text articles and disagreements were again managed via reviewer discussion prior to final inclusion or exclusion. The search protocol is summarized in Table 1.

\section{Excluded Studies}

Criteria for exclusion included:

- Failure to identify the inclusion criteria

- Non-English language

\section{Included Studies}

Criteria for inclusion included:

- Published last 10 years

- Controlled clinical trials and Cohort Studies

- Systematic Review

- Case Report

- Humans and animals

\section{Statistical Analysis}

The literature identified in this review does not meet criteria required for quantitative data or meta-analysis. Further, the heterogeneity of the case series prevents the plotting of outcomes to feature results.

\section{Results}

The Medline (PubMed) search identified 38 titles,23 were excluded with author agreement subsequent to title, abstract review.

Full-text versions of the 15 identified titles were obtained and evaluated independently by two reviewers 8 of the full-text articles were excluded based on the established criteria. This process identified 7 articles for inclusion and data extraction. The characteristic of included studies summarized in table 2.

\section{Table 1 Systematic Search Strategy}

\begin{tabular}{ll} 
Focus question: & $\begin{array}{l}\text { What is the effect of endocrine } \\
\text { disruptors on endometrial cells? }\end{array}$ \\
\hline Search strategy & $\begin{array}{l}\text { (endometrial cell) AND (endocrine } \\
\text { disruptor) }\end{array}$
\end{tabular}

\begin{tabular}{ll}
\hline Database search & \\
\hline Language & English \\
\hline Electronic & PubMed (Medline) \\
\hline Selection criteria & \\
\hline
\end{tabular}

\begin{tabular}{lll}
\hline Inclusion criteria & - & Published last 10 years \\
& Controlled clinical trials and \\
& & Cohort Studies \\
& - & Systematic Review \\
& Case Report \\
& - & Humans and animals \\
\hline Exclusion criteria & $\bullet$ & $\begin{array}{l}\text { Failure to identify the inclusion } \\
\text { criteria } \\
\text { Non-English language }\end{array}$ \\
& &
\end{tabular}


Table 2 Characteristic of Included Studies

\begin{tabular}{llll}
\hline Name Aim of study & $\begin{array}{l}\text { Total number of Treatment outcome } \\
\text { patient }\end{array}$
\end{tabular}

(Xiong et Determine the correlation al., 2020) between environmentally relevant levels of Bisphenol exposure and histone modification during endometrial stromal cells decidualization. B

(Aldad et Evaluate the effect of al., 2011) bisphenol-A (BPA), a xenoestrogen endocrine disruptor, on endometrial $\mathrm{P}$ receptor $(\mathrm{PR})$ expression in nonhuman primates and human cells.

$\begin{array}{ll}\text { (Helmesta } & \begin{array}{l}\text { Evaluate Bisphenol A } \\ \mathrm{m} \text { et al., } \\ \text { effects on human } \\ \text { endometrial endothelial } \\ \text { cell angiogenic activity }\end{array}\end{array}$

(Reed et al., Identifyhormonally2018) regulated miRs in endometrial stromal cells and to investigate the effects of BPA on selected miRs

(Mannelli Examined the potential et al., 2015) effects of an ED, bisphenol A (BPA), on endometrial maturation/decidualizatio $\mathrm{n}$, receptivity and secretion of decidual factors (biomarkers).

(Chou et Investigated whether BPA al., 2017) exposure can disrupt miRNA regulation and its gene expression regarding to EC carcinogenic progress.

(Yao et al., Evaluate the mechanism 2021) underlying adverse effects of ZEA in human decidual stromal cells and suggests RSV a potential therapeutic candidate to alleviate ZEA-induced cytotoxicity during decidualization.
6 patients (aged 4047 years) with regular menstrual cycle, who underwent surgery for early stage of cervical cancer.

10 adult female African green monkeys

five premenopausal women with regular menstrual cycles, who underwent hysterectomy for benign medical conditions

females $77 \quad(18-45$ years

undergoing

hysterectomy for benign conditions

\section{6 hysterectomy} specimens from different donors
This study provides that BPA exposure can regulate the expression of decidualization-related genes by affecting histone modification, impairing endometrial decidualization.

Bisphenol-A play a role as a weak estrogen. However, when administered with E2, BPA diminishes E2induced PR expression. The estrogen-like effect of BPA reported in exposed humans may be mediated by PR blockade and a resultant decrease in the estrogen inhibition normally imparted by P. Diminished PR expression may underlie previous reports linking BPA exposure to endometrial dysfunction in humans.

Bisphenol disturb endometrial vascular development and function, and subsequently endometrial actions important for normal function and successful implantation and placentation.

BPA and E2 downregulate miR-27b thereby leading to upregulation of genes important for vascularization and angiogenesis of the endometrium during the menstrual cycle and decidualization.

The multi-targeted disruption of BPA on decidual cells, at concentrations commonly detected in the human population, raises great concern about the possible consequences of exposure to BPA on the function of decidua and thus its potential deleterious effect on pregnancy.

miRNAs when underlying BPA exposure may play important roles in tumorigenesis.

Clinical strategies to relief negative effects of endocrine disruptor by applying RSV during decidualization, especially for women in preparation of getting pregnant. 


\section{Conclusion}

According the existing literatures, this study concluded that endocrine disruptors can affect on endometrial cells by regulate the expression of decidualization genes. But it can also cause endometrial dysfunction, disrupt vascular development and play important roles in tumorigenesis.

\section{Recommendation}

The existing literatures reporting on this are small in volume and can be considered of generally low quality. So, there is need for research comparing between presence or absence of endocrine disruptors and its directly affect positively or negatively in endometrial cells.

\section{References}

1. Aldad, T. S., Rahmani, N., Leranth, C., \& Taylor, H. S. (2011). Bisphenol-A exposure alters endometrial progesterone receptor expression in the nonhuman primate. Fertility and Sterility, 96(1), 175179.

https://doi.org/10.1016/j.fertnstert.2011.04 .010

2. Chou, W. C., Lee, P. H., Tan, Y. Y., Lin, H. C., Yang, C. W., Chen, K. H., \& Chuang, C. Y. (2017). An integrative transcriptomic analysis reveals bisphenol A exposure-induced dysregulation of micro RNA expression in human endometrial cells. Toxicology in Vitro, 41, 133-142.

https://doi.org/10.1016/j.tiv.2017.02.012

3. Chrousos, G. P. (2007). Organization and Integration of the Endocrine System: The Arousal and Sleep Perspective. In Sleep Medicine Clinics (Vol. 2, Issue 2, pp. 125145).

https://doi.org/10.1016/j.jsmc.2007.04.004

4. Clark, T. J., Mann, C. H., Shah, N., Khan, K. S., Song, F., \& Gupta, J. K. (2002). Accuracy of outpatient endometrial biopsy in the diagnosis of endometrial cancer: a systematic quantitative review. www.bjogelsevier.com

5. Colborn, T., vom Saal, F. S., \& Soto, A. M. (1994). Developmental Effects of Endocrine-Disrupting Chemicals in Wildlife and Humans. In Environmental Health Perspectives (Vol. 14, Issue 5).

6. Demeneix, B., National dHistoire Naturelle, M., Slama, R., Investigator, S., National Institute of Health, I., Research, M., Research Center, I., \& of Environmental Epidemiology, T. (2019). Endocrine Disruptors: from Scientific Evidence to Human Health Protection Policy Department for Citizens' Rights and Constitutional Affairs.

7. Gellersen, B., \&Brosens, J. J. (2014). Cyclic decidualization of the human endometrium in reproductive health and failure. In Endocrine Reviews (Vol. 35, Issue 6, pp. 851-905). Endocrine Society. https://doi.org/10.1210/er.2014-1045

8. Gomez-Fernandez, C. R., Ganjei-Azar, P., Averette, H. E., \& Nadji, M. (2000). Normal Endometrial Cells in Papanicolaou Smears: Prevalence in Women With and Without Endometrial Disease.

9. Helmestam, M., Davey, E., StavreusEvers, A., \&Olovsson, M. (2014). Bisphenol A affects human endometrial endothelial cell angiogenic activity in vitro. Reproductive Toxicology, 46, 6976.

https://doi.org/10.1016/j.reprotox.2014.03. 002

10. Hiller-Sturmhöfel, S., \&Bartke, A. (1998). The Endocrine System An Overview.

11. la Rocca, C., Tait, S., Guerranti, C., Busani, L., Ciardo, F., Bergamasco, B., Perra, G., Mancini, F. R., Marci, R., Bordi, G., Caserta, D., Focardi, S., Moscarini, M., \&Mantovani, A. (2015). Exposure to endocrine disruptors and nuclear receptors gene expression in infertile and fertile men from Italian areas with different 
environmental features. International Journal of Environmental Research and Public Health, 12(10), 12426-12445. https://doi.org/10.3390/ijerph121012426

12. Mallozzi, M., Leone, C., Manurita, F., Bellati, F., \& Caserta, D. (2017). Endocrine disrupting chemicals and endometrial cancer: An overview of recent laboratory evidence and epidemiological studies. In International Journal of Environmental Research and Public Health (Vol. 14, Issue 3). MDPI AG. https://doi.org/10.3390/ijerph14030334

13. Mannelli, C., Szóstek, A. Z., Lukasik, K., Carotenuto, C., Ietta, F., Romagnoli, R., Ferretti, C., Paulesu, L., Wołczynski, S., Jan Skarzynski, D., \& Author, C. (2015). Bisphenol-A modulates receptivity and secretory function of human decidual cells: an in vitro study. http://www.pan.olsztyn.pl/en/drip

14. Markey, C. M., Rubin, B. S., Soto, A. M., \& Sonnenschein, C. (2002). Endocrine disruptors: From Wingspread to environmental developmental biology. Journal of Steroid Biochemistry and Molecular Biology, 83(1-5), 235-244. https://doi.org/10.1016/S09600760(02)00272-8

15. Monneret, C. (2017). What is an endocrine disruptor? In Comptes Rendus - Biologies (Vol. 340, Issues 9-10, pp. 403-405). Elsevier Masson SAS. https://doi.org/10.1016/j.crvi.2017.07.004

16. Reed, B. G., Babayev, S. N., Chen, L. X., Carr, B. R., Word, R. A., \& Jimenez, P. T. (2018). Estrogen-Regulated miRNA-27b Is Altered By Bisphenol A In Endometrial Stromal Cells.

17. Tyler, C. R., Jobling, S., Sumpter, J. P., \& Tyler, C. (1998). Endocrine Disruption in Wildlife: A Critical Review of the Evidence. In Critical Reviews in Toxicology (Vol. 28, Issue 4).
18. WHO | World Health Organization. (2002). Retrieved January 9, 2021, from https://www.who.int/ipcs/publications/new _issues/endocrine_disruptors/en/

19. Xiong, Y., Wen, X., Liu, H., Zhang, M., \& Zhang, Y. (2020). Bisphenol a affects endometrial stromal cells decidualization, involvement of epigenetic regulation. Journal of Steroid Biochemistry and Molecular Biology, 200. https://doi.org/10.1016/j.jsbmb.2020.1056 40

20. Yao, S., Wei, W., Cao, R., Lu, L., Liang, S., Xiong, M., Zhang, C., Liang, X., \& Ma, Y. (2021). Resveratrol alleviates zeainduced decidualization disturbance in human endometrial stromal cells. Ecotoxicology and Environmental Safety, 207.

https://doi.org/10.1016/j.ecoenv.2020.1115 11 